\title{
DISINFECTION ACTION OF SOME ESSENTIAL OILS ON STAINLESS STEEL Anita Vidács ${ }^{1}$, JuditKrisch ${ }^{2}$, Csaba Vágvölgyi ${ }^{1}$
}

\author{
${ }^{1}$ Departmentof Microbiology, Faculty of Science and Informatics, University of Szeged, \\ 6726, 52 Középfasor, Szeged, Hungary \\ ${ }^{2}$ Institute of Food Engineering, Faculty of Engineering, University of Szeged, 6724, 7 Mars \\ tér, Szeged, Hungary \\ e-mail:anitavidacs@gmail.com
}

\begin{abstract}
Bacteria can attach to different surfaces and form biofilm. Biofilms can cause a big problem in food industry by contamination of food items and reduction of the effectiveness of machines. In the biofilm bacteria are less exposed to the different disinfectants, than the free living cells. Essential oils (EO) with known antimicrobial effect can also inhibit biofilm formation. In our experiments minimal inhibitory concentrations (MIC) and minimal bactericide concentrations (MBC) of the investigated EOs: cinnamon, juniper and lemon were determined by macro-dilution method on Pseudomonas putida and E.coli. Cinnamon showed the best antibacterial effect with $\mathrm{MBC}$ values of $2 \mathrm{mg} / \mathrm{ml}$ for $E$. coli and $4 \mathrm{mg} / \mathrm{ml}$ forP.putida. Thebactericidaleffect of EOsdependedontheactingtime. We established 80 minutes forP. putida and 120 (cinnamon EO) and 240 (juniper EO) min forE. coli. The disinfection potential of the EOs were studied on P. putida and E. coli 1 and 7 days old biofilms formed on industrial stainless steel surfaces. Each of the EO was effective. The number of $P$. putida cells was reduced up to $99 \%$ and we had similar result by 1 day old $E$. coli biofilm. The cell number of 7 days old $E$. coli biofilm was reduced by $62.5 \%$ with cinnamon EO and juniper EO reduced it by $87 \%$.
\end{abstract}

Keywords: biofilm, essential oils, MIC/MBC, stainless steel

\section{INTRODUCTION}

Bacteria can attach to different surfaces and form biofilm, which can contaminate equipment surfaces and food. In the biofilm bacteria are more resistant to disinfection, than as a single cell (Kumar and Anand, 1998). Biofilm formation can cause a big industrial problem mainly in the food industry (Van Houdt and Michiels, 2010), where accumulation of pathogenic bacteria leads to a food safety concern. The efficiency of processes can also be reduced (reduced membrane permeability, corrosion) (Simoes et al., 2009).

Biofilms can be reduced by chemical substances (sodium hypochlorite), natural materials (surfactant) (Simoes et al., 2009) or physical methods (ionizing radiation). By the disinfection EPS (extracellular polymeric substances) have to be removed, because the EPS is a barrier and protects the cells in the matrix. Survival bacteria can build a new matrix and will give the resistance to the other microorganisms. The disinfection action is depending on the temperature, $\mathrm{pH}$, humidity, acting time and resistance(Van Houdt and Michiels, 2010). The used antimicrobials need to be safe, non-toxic and easily to remove from the surfaces(Simoes et al., 2009).

Most of the essential oils (EO) together with other plant extracts are well-known antimicrobials (Burt, 2004). The mechanism of action is coagulation of the cytoplasm, reduction of the integration of cell wall and membrane, leading toloss of cell components and death of the cell (Bakkali et al., 2008). 
The aim of our study was to investigatethe disinfection effect of selected essential oils on stainless steel surface.

\section{MATERIALS and METHODS}

\section{Materials}

The biofilm forming Gram negative bacteria:Escerichia coli and Pseudomonas putidagrowing on LB (in g/l: $\mathrm{NaCl} \mathrm{10}$; casein peptone 10 and yeast extract 5) or on TGE (glucose 10, peptone 5 , yeast extract $2.5 \mathrm{~g} / \mathrm{l}$ ) medium were used. E.coli was incubated for $18-20 \mathrm{~h}$, at $37^{\circ}$ Cand P.putida at $25^{\circ} \mathrm{C}$.

Cinnamon, juniper and lemon essential oils were purchased from the Aromax Natural Products Zrt. (Budapest, Hungary).

Stainless steel coupons in the size of $2 \times 2 \mathrm{~cm}$ from food industryequipments were defatted with EtOH and sterilized at $121^{\circ} \mathrm{C}$ for $20 \mathrm{~min}$.

\section{Methods}

Determination of MIC/MBC values was done by macro dilution method using essential oils in the concentration range of $1-60 \mathrm{mg} / \mathrm{ml}$. Bacterial suspensions $\left(10^{5} \mathrm{cfu} / \mathrm{ml}\right)$ were mixed with different concentration of essential oil, and 1\% Tween 40 was added to aid dispersion of the oil. After incubation for 24hturbidity in the tubes was examined and clear tubes were declared having the MIC concentration. MBC values were determined by spreading100 $\mu 1$ suspension from the clear tubes on Petri dishes. After $24 \mathrm{~h}$ incubation colony number was counted andthe concentration where no colony was foundrepresented the $\mathrm{MBC}$ value. Establishment of disinfection time: the effect of essential oils in $\mathrm{MBC}$ on bacterial cell suspension $\left(10^{5} \mathrm{cfu} / \mathrm{ml}\right)$ was checked after $20,40,60,120$ minutes.

Biofilm inhibition:bacteria were growing on sterile stainless steel coupons in culture medium (P. putida TGE broth, E. coli LB broth) at $24 \mathrm{~h}$ and $168 \mathrm{~h}$. After incubation coupons were rinsed with distilled water to remove non-attached bacteria from the surface. Coupons were transferred to a disinfectant solution containing essential oils in MBC concentration. After disinfection time established in previous experiments biofilms on the coupons were scrapped off by sterile applicator swab which was transferred to a tube with sterile peptone water. After one hour cotton swabs were gentle pushed out and cfuwas determined by spreading $100 \mu 1$ cell suspension on Petri dishes.

\section{RESULTS and DISCUSSION}

All the essential oils had good antibacterial effect (Table 1).In our experiments cinnamon EO had the lowest MIC and MBC values.

Table $1 \mathrm{MIC} / \mathrm{MBC}(\mathrm{mg} / \mathrm{ml})$ values of the investigated essential oils

\begin{tabular}{|c|c|c|c|c|}
\hline \multirow{2}{*}{ Essential oil } & \multicolumn{2}{|c|}{ P. putida } & \multicolumn{2}{c|}{ E. coli } \\
\cline { 2 - 5 } & MIC & MBC & MIC & MBC \\
\hline Cinnamon & 2 & 4 & 1 & 2 \\
\hline Juniper & 27 & 54 & 13,5 & 27 \\
\hline Lemon & 27 & 54 & $>27$ & $>54$ \\
\hline
\end{tabular}

Lemon EO was excluded from further investigations on $E$. coli, because of the very high MBC. 


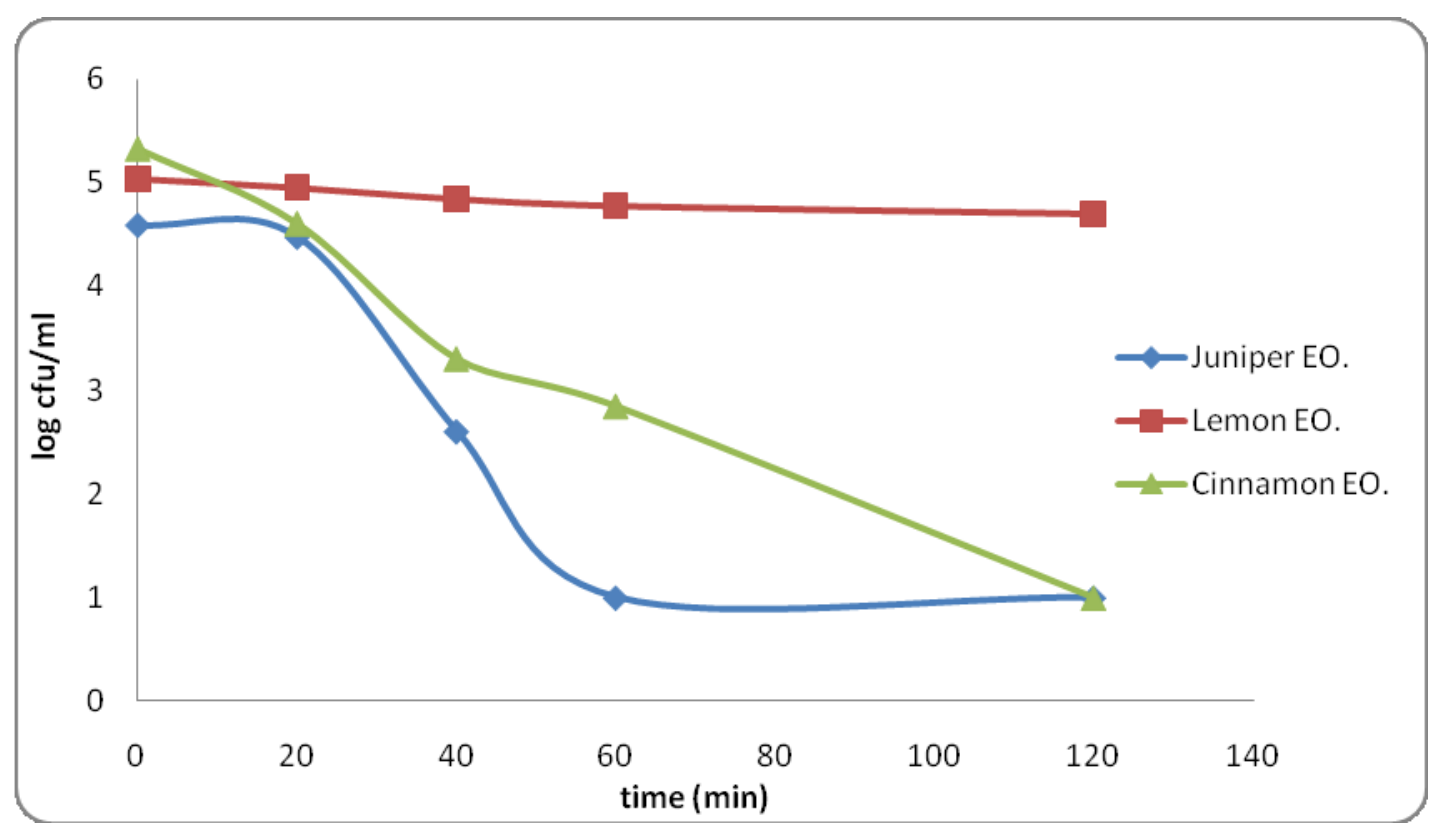

Figure 1 Time killing curves for P. putida

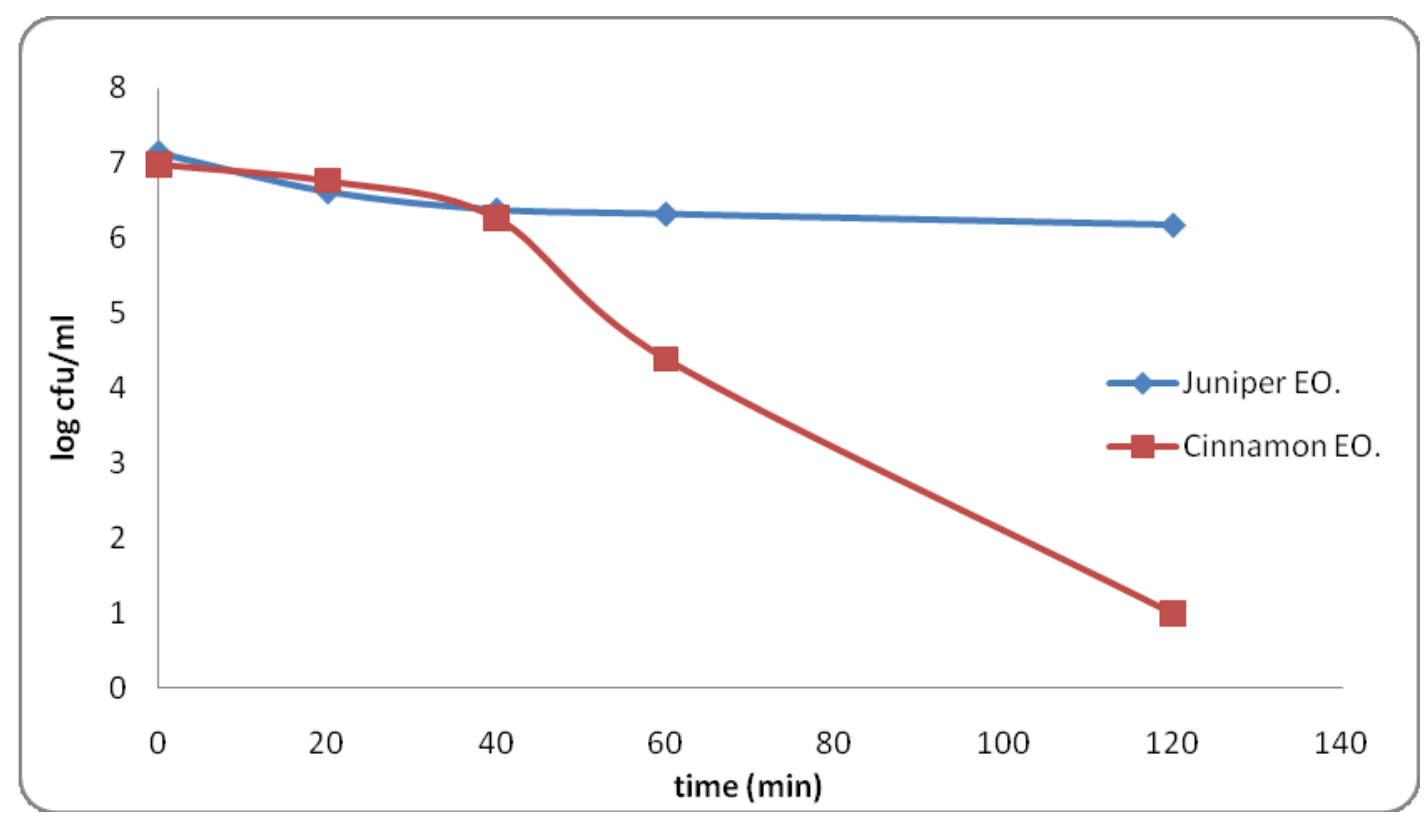

Figure 2 Time killing curves for $E$. coli

On the Figures 1 and 2 you can see the time killing curves for P. putida and E.coli. It can be seen that juniper and cinnamon EO had the best effect causing a fast linear degradation of the living cell number while lemon EO had only limited effect during the time of investigation on P. putida.

For the reduction of young and matured biofilms we used 80 minutes exposure timefor $P$. putida and 120 (cinnamon EO) and 240 (juniper EO) min for E. coli (Table 2). 
Table 2 Reduction of living cell number of $P$. putida and E. colibiofilms [cfu/ml $/ \mathrm{cm}^{2}$ ]

\begin{tabular}{|c|c|c|c|c|c|}
\hline Bacteria & Biofilm age & control & cinnamon EO & juniper EO & lemon EO \\
\hline \multirow{2}{*}{ P. putida } & 1 day & $8.8 \times 10^{3}$ & $7.5 \times 10^{1}$ & $<10$ & $<10$ \\
\cline { 2 - 6 } & 7 days & $2.5 \times 10^{4}$ & $1.4 \times 10^{2}$ & $2 \times 10^{2}$ & $2.5 \times 10^{2}$ \\
\hline \multirow{2}{*}{ E. coli } & 1 day & $2.6 \times 10^{3}$ & $<10$ & $<10$ & - \\
\cline { 2 - 6 } & 7 days & $5 \times 10^{3}$ & $1.9 \times 10^{3}$ & $6.5 \times 10^{2}$ & - \\
\hline
\end{tabular}

Table 2 shows the biofilm disrupting potential of essential oils.It can be seen that matured biofilmshad limited sensibility to the EOs.P. putida biofilm ( $24 \mathrm{~h}$ and $168 \mathrm{~h}$ old) was reduced by $99 \%$ after 80 min disinfection time. We got smaller percent by $168 \mathrm{~h}$ old E. coli (cinnamon EO $62.5 \%$; 120min, juniper EO $87 \%$; 240min treatment), but the younger biofilm had same reduction, than $P$. putida.

Our result was compared with the other study, where Listeria monocytogenes biofilm was reduced by lemongras EO. 3h old biofilm colony decreased by $40.28 \%$ after 15 min treatment, after 60 min this percent was 44.58 , by $240 \mathrm{~h}$ old biofilm this number was lower $(26.59 \%$ $15 \mathrm{~min}$ ), but after $60 \mathrm{~min}$ it was $72.51 \%$ (de Oliveira et al., 2010).

In the future we will extend our investigations on mixed culture biofilms and it is also planed to use essential oil mixes instead of single oil. In this way we can establish the interaction between different EOs or between EOS and other plant-derived components.

\section{REFERENCES}

Bakkali, F. Averbeck, S., Averbeck, D., Idaomar, M. (2008): Biological effects of essential oils- A review. Food and Chemical Toxicology 46, 446-475.

Burt, S. (2004) Essential oils: their antibacterial properties and potential applications in foods - a review. Int.J.FoodMicrobiol. 94:223-253.

Kumar CG., Anand, SK. (1998): Significance of microbial biofilms in food industry: a review. International Journal of Food Microbiology, 42 (1-2), 9-27.

de Oliveira, MMM., Brugnera, DF., Cardoso, MdG., Alves, E., Piccoli, RH. (2010): Disinfectant action of Cymbopogonsp. essential oils in different phases of biofilm formation by Listeria monocytogeneson stainless steel surface. Food Control 21, 549553.

Solórzano-Santos, F., Guadalupe, M., Novales, M. (2012): Essential oils from aromatic herbs as antimicrobial agents. Current Opinion in Biotechnology 23(2), 136-141.

Simoes, M., Simoes, LC., Vieira, MJ. (2009): A review of current and emergent biofilm control strategies. LWT-Food Science and Technology 43, 573-583.

Van Houdt, R. and Michiels, CV. (2010): Biofilm formation and the food industry, a focus on the bacterial outer surface Review article. Journal of Applied Microbiology; 109 (4):1117-31. 